
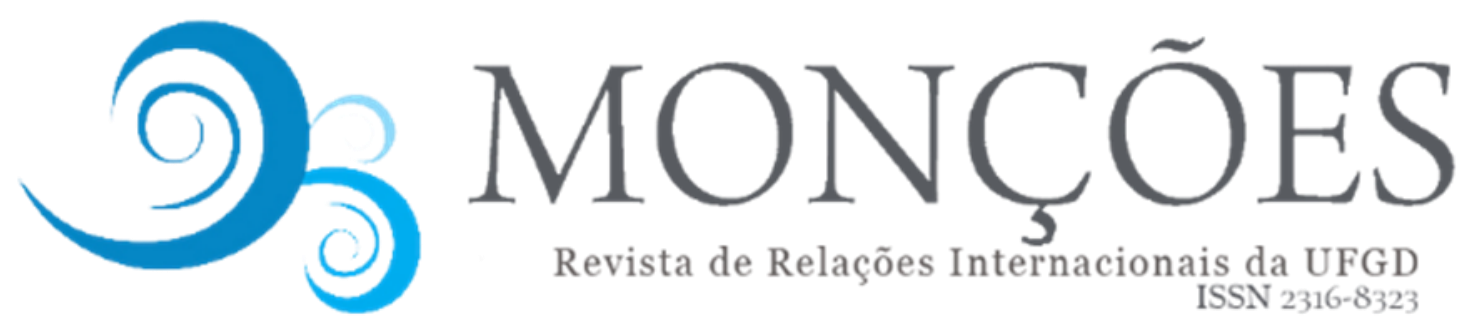

Revista de Relações Internacionais da UFGD

ISSN 2316-8323

\title{
ABORDAGEM DOS MUITOS MUNDOS APLICADA AO ESTUDO DA POLÍTICA AMBIENTAL GLOBAL NO ANTROPOCENO: VOZES INDÍGENAS NA AMAZÔNIA ${ }^{1}$
}

\author{
CRISTINA YUMIE AOKI INOUE 2 \\ Professora-Associada do Instituto de \\ Relações Internacionais da Universidade de \\ Brasília
}

Tradução de Rafael Alexandre Mello (UnB) ${ }^{3}$

Revisão técnica de João Nackle Urt (UFGD) ${ }^{4}$

\begin{abstract}
RESUMO: Muitas lutas socioambientais ao redor do mundo abraçam esforços em prol da proteção contra o desaparecimento de outros "mundos". Ao lado da diversidade biológica, encontram-se ameaçadas as línguas, as tradições, os conhecimentos humanos, assim como as relações íntimas entre povos e suas terras, por várias formas de colonização, expansão do capital, ou simplesmente a globalização de estilos de viver. Estudiosos das relações internacionais começaram a despertar para o entendimento de que o mundo é composto por muitos mundos, e que essa diversidade se encontra ameaçada por fortes pressões. Este esforço tem sido essencial para a compreensão da luta em prol da manutenção desses muitos mundos em um único Planeta Terra. No entanto, esses estudos ainda não penetraram por completo os estudos de Política Ambiental Global (PAG). Este artigo expande essa sensibilidade e esforço acadêmico à PAG, ao dialogar com formas indígenas de conhecer. Defende-se que as lutas indígenas são lutas pela sobrevivência de muitos mundos em um único planeta e que há o que se aprender disso. Não se busca generalizar o conhecimento indígena, mas sim lançar uma chamada ao engajamento. Por meio da Escuta e da Fala Criativas, uma metodologia da abordagem dos muitos mundos, este artigo põe em foco o mundo-floresta dos Yanomami e apresenta algumas perspectivas para ilustrar como ontologias relacionais e histórias de divindades dialógicas e não hierárquicas, constroem formas de conhecer e de ser a partir das quais podemos aprender a nos relacionar com o Planeta Terra em pé de igualdade.
\end{abstract}

\footnotetext{
${ }^{1}$ N.T. Originalmente publicado em inglês com título "Worlding the Study of Global Environmental Politics in the Anthropocene: Indigenous Voices from the Amazon", na revista Global Environmental Politics v. 18, n. 4, 2018, p. 25-42. A Revista Monções agradece à MIT Press pela permissão concedida para publicar esta tradução.

${ }^{2}$ Reconheço e expresso meus sinceros agradecimentos a Michele Betsill, Jonathan Gamu, Peter Jacques, Kate O'Neill, Dimitris Stevis, Paul Wapner e, finalmente, aos quatro revisores anônimos e aos editores do GEP por sugestões, comentários, edições e orientação. Agradeço também ao Instituto de Relações Internacionais da Universidade de Brasília, a Universidade Estadual do Colorado e às agências brasileiras CNPq e CAPES pelo apoio. Por fim, gostaria de agradecer a Carolina Pinheiro e à saudosa Lily Ling, que juntas desenvolveram o conceito de Creative Listening and Speaking.

${ }^{3}$ Contato: r.moreira.demello@gmail.com

${ }^{4}$ Contato: joaourt@gmail.com
} 
O romance de Ursula K. Le Guin, Floresta é o nome do mundo, conta a história de nativos que viviam em Athshe, um planeta formado por densas florestas e longe da Terra, testemunhando a destruição de suas terras e de seu modo de vida. $O$ romance descreve como os Terrans, futuros humanos, viajaram a Athshe para cortar as árvores do planeta (e enviá-las de volta ao Planeta Terra) e preparar o terreno para os futuros colonizadores Terrans. Dois athsheanos conversam sobre a sanidade dos Terrans:

\begin{abstract}
"Um povo não pode ser louco."
"Mas eles só sonham dormindo, você disse; quando querem sonhar acordados, tomam venenos para que os sonhos saiam fora de controle, você disse! As pessoas podem ser mais dementes? Eles não distinguem o tempodos-sonhos do tempo-do-mundo, e nisso não se diferenciam de um neném. Talvez, ao matarem uma árvore, pensem que ela voltará à vida!" (LE GUIN, 1976, capítulo II)
\end{abstract}

Assim como os fantasiosos athsheanos de Le Guin, muitos povos indígenas ao redor do mundo ${ }^{5}$ se consideram povos da floresta e lutam para manter a posse de suas terras, florestas, água, montanhas, conhecimento e modos de ser. De fato, muitos povos indígenas no Brasil se definem como povos da floresta ${ }^{6}$ e estão constantemente resistindo à apropriação, exploração e expulsão. Para os Yanomami, por exemplo, a palavra para natureza é floresta, e a floresta é o seu mundo (DANOWSKI; VIVEIROS DE CASTRO, 2017). Seu sistema de conhecimento trata de sonhos, espíritos, animais e outros seres associados à terra, e eles se enxergam como um entre muitos dos povos e entidades da floresta. Do ponto de vista teórico, pode-se dizer que sua visão de mundo desvia do antropocentrismo e reconhece o significado político da diversidade da floresta.

\footnotetext{
${ }^{5}$ Le Guin contou que o Dr. Charles Tart, que escreveu Altered States of Consciousness, perguntou a ela se a história de Athsheans era baseada no povo Senoi da Malásia. Ela pensou que estava inventando seus próprios "alienígenas imaginários", mas para o Dr. Tart, ela estava descrevendo os Senoi (LE GUIN, 1976). Pode haver muitos povos cuja palavra para mundo é floresta.

${ }^{6}$ Para Krenak (2015), os primeiros povos da floresta são os povos indígenas. Depois, outros grupos começaram a se identificar da mesma forma. Atualmente a Aliança dos Povos da Floresta, instituída em 1989, reúne povos indígenas e seringueiros, que lutam por suas terras e territórios e pela proteção da floresta amazônica. Veja www.ipam.org.br/noticias/Povos-das-Florestas-historia-de-umaalianca / 219, último acesso em 9 de abril de 2014.
} 
Para os Yanomami ${ }^{7}$, urihi a é a terra florestal e urihinari é a sua imagem, o espírito da floresta, visível apenas para os xamãs. Os xamãs nos contam que, para os Yanomami, a floresta é um ser senciente, que faz parte de uma dinâmica cosmológica complexa que engloba as inter-relações do homem com os demais seres; sente dor, reclama e suas árvores altas gemem e choram de dor quando queimadas (KOPENAWA; ALBERT, 2013, p. 311, 382, 388) ${ }^{8}$. No início, quando a floresta era jovem, alguns de seus ancestrais se metamorfosearam em animais e outros seres: "Humanos-queixada viraram queixadas; humanos-veado viraram veados; humanos-cutia viraram cutias" ${ }^{9}$, e assim por diante (KOPENAWA; ALBERT, 2013, p. 60-61). Para os Yanomami, "são esses ancestrais tornados outros que caçamos e comemos hoje em dia" (KOPENAWA; ALBERT, 2013, p. 61). Estas são apenas suas peles; pois suas imagens, (espíritos), xapiri, são seus verdadeiros corações e verdadeiras partes internas, que são imortais (KOPENAWA; ALBERT, 2013).

Segundo Kopenawa, os "brancos" não compreendem o porquê de os Yanomami quererem preservar sua floresta (KOPENAWA; ALBERT, 2013). Para eles, o significado da floresta está para além do sequestro de carbono ou do estoque de madeira, e o valor intrínseco da biodiversidade não se reduz aos seus usos medicinais, alimentícios, científicos ou recreacionais. A floresta não é enxergada como um "ambiente" que os circunda, mas sim seu lar, de fato seu mundo. A diversidade biológica, cognitiva e física da floresta, ao lado das relações entre as árvores, o solo, a água, os animais, os seres humanos, e os espíritos, constituem o próprio tecido do seu viver. O problema se encontra em muitos não indígenas não enxergarem isso. Sem conseguirem fundir horizontes ecossociais, os Yanomami resistem a ameaças às suas terras postas pelo garimpo, o desenvolvimento de infraestrutura, o agronegócio, e tentativas de apropriação e posterior alteração de

\footnotetext{
7 Os Yanomami vivem na Amazônia setentrional, em uma área entre as fronteiras do Brasil e da Venezuela. No conjunto, suas terras cobrem 17,9 milhões de hectares, tornando-se uma das maiores Terras Indígenas com cobertura de floresta do planeta.

${ }^{8}$ N. T. Nas passagens de $A$ Queda do Céu, cita-se a edição brasileira, com a tradução de Beatriz Perrone-Moisés. Ver Davi Kopenawa e Bruce Albert, A queda do céu. Palavras de um xamã Yanomami, São Paulo: Companhia das Letras, 2015, 729 p.

${ }^{9}$ N. T. Na edição brasileira, p. 117.
} 
seus conhecimentos e seus significados. Precisam defender seu mundo num contexto de uma tendência generalizada de homogeneização de mundos.

Há muitas lutas socioambientais mundo afora como a dos Yanomami que englobam esforços de proteção contra o desaparecimento de outros mundos. Ao lado da diversidade biológica, também se encontram sob ataque línguas humanas, tradições, conhecimentos, e íntimas relações entre povos e suas terras, ameaçados por diferentes formas de colonização, expansão de capital, ou simplesmente a globalização de estilos de viver. Acadêmicos das relações internacionais começaram, há pouco tempo, a apreender que o mundo é composto por muitos mundos e que ${ }^{10}$ fortes pressões se sobrepõem a essa diversidade para reduzi-la. Faz parte disso reconhecer o processo de erradicação pelo qual o conhecimento e o poder privilegiados atropelam os mundos dos vulneráveis ou mesmo dos que detém menos poder. Esse esforço tem se mostrado essencial para a compreensão da luta pela continuidade desses muitos mundos em um único Planeta Terra. No entanto, tais pesquisas ainda estão por integrar plenamente os estudos de Política Ambiental Global (PAG). Este artigo vai no sentido de estender tal sensibilidade e esforço intelectual à PAG.

A abordagem dos muitos mundos ${ }^{11}$ engloba os processos que buscam tornar o mundo mais inteligível e determinar um "nós" por oposição aos "outros" e em que medida tais processos de construção de sentido constituem os mundos em que vivemos (INOUE; TICKNER, 2016). Nesse sentido, teorias e conceitos são partes constitutivas de nossos mundos. É importante expor nossas concepções "políticomundiais" porque situam o que importa e o que não importa, o que faz parte do nosso mundo e do nosso tempo e quem está excluído (TICKNER; BLANEY, 2012, p. 9). Abordar os muitos mundos é um processo duplo que envolve autorreflexão e diálogo. Primeiro, nos encoraja a questionar nossos próprios conceitos e suposições para

\footnotetext{
${ }^{10}$ Exemplos incluem Acharya e Buzan (2010); a série de livros Worlding Beyond the West; as pesquisas do Teaching, Research, and International Politics; e o tema da convenção anual da International Studies Association de 2015 "RI Global e Mundos Regionais: Uma Nova Agenda para Estudos Internacionais".

${ }^{11}$ N.T. O conceito de worlding tem sido traduzido de diversas formas, para o português e o espanhol. Em espanhol, encontramos as traduções mundificar e componer los mundos. Em português, já se empregou mundianizar, mundanizar e mundar, assim como construções que evitam conceitualizar, como visões de mundo e abordagem de múltiplos mundos. Optamos aqui por traduzir worlding como a abordagem dos muitos mundos.
} 
entender como nossas noções estão situadas no tempo e no espaço. Em segundo lugar, envolve ampliar nossa visão no tempo e no espaço para descobrir o que está ocultado por esses conceitos e suposições, reconhecendo que o nosso é apenas um entre muitos mundos. Precisamos ir para as "margens críticas" e abrirmo-nos aos "outros possíveis mundos ou formas de viver que são representados como implausíveis, ideológicos ou espúrios e que, muitas vezes, são lançados aos domínios da ficção, da fantasia ou do absurdo" (TICKNER; BLANEY, 2012, p. 9).

Há um consenso geral de que estudar PAG significa compreender ou explicar conflitos de interesse entre diferentes atores (CONCA; DABELKO, 2015, p. 3; DAUVERGNE, 2005; CHASEK et al., 2017). Conca e Dabelko (2015, p. 2) observam que existem diferentes visões sobre a floresta, e a maneira em que essas diferenças se desenrolam define a "matéria da política". No entanto, as florestas e outros ecossistemas (rios, montanhas, savanas, geleiras) parecem meramente ser vistos por nós, estudiosos da PAG, como estoques de carbono, recursos naturais, biodiversidade e localidades de subsistência, mas não como mundos em si. Mesmo a suposição de que existem diferentes visões de mundo ainda não tem sido contemplada com profundidade. Para além de reconhecer a existência de muitos mundos, poderíamos aprender ao engajarmos com eles, caminhando em direção a uma "ecologia de saberes" (SANTOS, 2016). O diálogo com as formas indígenas de conhecer pode nos ajudar a desenvolver entendimentos mais híbridos sobre 0 conhecimento científico e a relação natureza-sociedade (WAPNER, 2014; RUDY; WHITE, 2014).

A PAG, como campo, poderia ganhar com esse diálogo. ${ }^{12}$ Há poucos que investigam os povos indígenas (e outros grupos marginalizados) como constituintes de mundos, e menos ainda o que isso poderia significar para o estudo da PAG. Nesse sentido, este artigo tem como objetivo abordar a PAG pela perspectiva dos muitos mundos, dialogando com formas indígenas de conhecer e reconhecê-las em paridade epistemológica e ontológica com o conhecimento acadêmico. ${ }^{13}$ Defendo que as lutas

\footnotetext{
12 Entre 2001 e 2016, apenas 4 dos 427 artigos publicados na revista Global Environmental Politics discutiram questões indígenas (ver MARTELLO, 2001; SCHLOSBERG; CARRUTHERS, 2010; KAUFFMAN; MARTIN, 2014; SUISEEYA, 2014).

${ }^{13}$ Ling (2014) argumenta que a paridade epistemológica e ontológica ocorre quando todos têm agência discursiva.
} 
indígenas são lutas pela sobrevivência de muitos mundos em um planeta e que podemos aprender com esta luta. Minha intenção não é traçar uma generalização sobre o conhecimento indígena, mas sim fazer um apelo ao engajamento, apresentando algumas perspectivas para ilustrar como seus mundos relacionais, histórias de divindades não hierárquicas e dialógicas, constroem mundos a partir dos quais podemos aprender a nos relacionar com o Planeta Terra em pé de igualdade. A título de exemplo, o antropomorfismo indígena ${ }^{14}$ nos ensina sobre o não excepcionalismo dos seres humanos e que a "natureza" é uma sociedade de sociedades. Para evitar os riscos de tratar o conhecimento indígena como um objeto a ser isolado e armazenado em bancos de dados, ou como um recurso a ser extraído, devemos reconhecer os povos indígenas como atores e conhecedores que possuem voz e agência. Nesse sentido, apresento as noções de Escuta e Fala Criativas ${ }^{15}$ (EFC) e de "terceiro espaço" (LING; PINHEIRO, no prelo) ${ }^{16}$, onde todos dispõem de agência discursiva. Para Ling e Pinheiro, o terceiro espaço, ou o "oásis global que atravessa vários mundos", pode ser um local real ou imaginário onde as assimetrias são postas de lado para que a mutualidade possa se desenvolver e outras formas de pensar e fazer, de ser e se relacionar, possam emergir. ${ }^{17}$

O foco deste artigo está no mundo-floresta dos Yanomami e na luta pela manutenção de sua posse. Exemplos de sistemas de conhecimento indígenas são apresentados como evidências de formas de saber mais sintonizadas com os desafios trazidos pela crise socioambiental planetária. Considerar a existência de mundos indígenas é importante para a PAG não porque as formas indígenas de conhecer sejam recursos úteis, ou por sua proximidade com a natureza (ecoindigenismo); mas sim porque suas formas de conhecer e ser no planeta podem contribuir para compreensões acerca da política planetária no Antropoceno que enfatizam o não excepcionalismo dos seres humanos e todas as relações políticas que decorrem de tais compreensões (NICHOLSON; JINNAH, 2016). Foram utilizadas fontes primárias e secundárias, tais

\footnotetext{
${ }^{14}$ Discutirei a ideia de antropomorfismo posteriormente, mas adianto que se refere à maneira como os povos indígenas veem uma origem humana comum para tudo. Os humanos se transformaram em animais, plantas, estrelas, a lua, o sol e assim por diante.

${ }^{15}$ N.T. No original, Creative Listening and Speaking.

${ }^{16}$ N.T. O texto de Ling e Pinheiro foi publicado em 2020.

${ }^{17}$ Ling e Pinheiro utilizam o termo cunhado por Edward Soja, que propõe uma terceira forma de pensar os espaços, englobando as dimensões material e social, para além do pensamento dual que predominou na geografia. O terceiro espaço refere-se agora a empreendimentos híbridos urbanos.
} 
como documentos de organizações que trabalham com povos indígenas, bem como escritos acadêmicos e não acadêmicos de líderes indígenas, acadêmicos (principalmente antropólogos) e xamãs.

Este artigo está dividido em três partes. Na primeira, apresento a noção de muitos mundos, a partir dos quais acadêmicos podem se envolver na co-produção de conhecimento por meio da EFC. Logo, desenvolvo um esforço para imaginar a PAG como um "terceiro espaço", no qual a relacionalidade, a ressonância e a interexistência atuam para nos ajudar a ouvir as vozes indígenas e perceber como os sonhos, a queda do céu, o antropomorfismo e o mundo-floresta ressoam junto ao destino da floresta amazônica e a noção do Antropoceno. Nas considerações finais, enfatizo que as lutas indígenas para manter o mundo-floresta são tanto lutas materiais pela terra, a floresta, a água e os animais quanto lutas ideacionais sobre formas de conhecer e ser, e que ambas são intrinsecamente uma só. Reconhecer a existência desses mundos não é suficiente, e os estudiosos da PAG podem criar esses terceiros espaços para se envolver com esses mundos, o que resultaria em aprendizagem mútua.

\section{Múltiplos mundos e formas de conhecer: aprender pela EFC}

Dado que os impactos da humanidade no Planeta Terra são tão grandes que lugar algum permanece intocado, estudiosos apontam para o fim da natureza como um conceito útil e para a necessidade de reconceitualizar a dicotomia naturezasociedade (LEIS, 1999; WAPNER, 2010, 2014; RUDY; WHITE, 2014, p. 129). Referem-se ao hibridismo, ou ao entendimento de que "coisas, sociedades, naturezas e tecnologias estão misturadas e mescladas" (RUDY; WHITE, 2014, p. 129). O Antropoceno desafia a noção de política ambiental que evoluiu em torno dessa dicotomia. É necessário um meio-termo baseado nas relações com o "mais do que humano" (WAPNER, 2014, p. 43, 46). Outras formas de conhecer podem nos trazer novas possibilidades para entender a política planetária.

Essas formas outras de conhecer são rejeitadas por muitos, que as categorizam como mitos, histórias, superstições, senso comum ou, simplesmente, as relegam ao reino da "irracionalidade"; ao fazer isso, os monopólios de reivindicações 
de verdade são mantidos (CESARINO et al., 2013). Neste sentido, Ramos (2013, p. 25-26) nos lembra que "a ascensão do racionalismo [...] 'é um exemplo fascinante da tentativa de transcender, desvalorizar e descartar formas complexas de pensamento e experiência'”. No entanto, ao avançar a parcimônia, a objetividade e a neutralidade, também ignoramos a importância ontológica de "espíritos, batalhas, ideias, deuses, arco-íris, dores, minérios, planetas, animais, festividades, justiça, destino, doença, divórcios, o céu, a morte, o medo". ${ }^{18}$

Santos (2016) propõe as "epistemologias do Sul" (ES) como meio de se engajar nas formas de conhecer de quem sofre injustiças, dominação e opressão. Para o autor, a transformação epistemológica pode "reinventar a emancipação social em escala global" (p. 18). Falar de múltiplos saberes, ou epistemes, significa atentar para as múltiplas ontologias, ou que existem múltiplas realidades, o pluriverso, em contraste com a suposição de um único universo com múltiplas culturas, perspectivas ou representações subjetivas (ESCOBAR, 2016, p. 13).

As lutas socioambientais que compreendem os povos indígenas são lutas para manter formas de saber (SANTOS, 2016; MARTINEZ-ALIER, 2002) e, de forma mais ampla, para garantir a sobrevivência de muitos mundos. Nessas lutas, a diversidade de alternativas de vida é ignorada porque nossas teorias e conceitos não as identificam como "contribuições válidas para uma sociedade melhor" (SANTOS, 2016, p. 20). Esta questão é epistemológica porque não consideramos essas formas de conhecimento como conhecimento, mas sim as classificamos como superstições, opiniões, subjetividades ou senso comum.

O referencial das ES se propõe a unir diferentes sistemas de conhecimento: científico, popular, artístico e performativo, entre outros (SANTOS, 2016). Há tendências na teoria crítica contemporânea que apontam para a necessidade de aprender tanto com a experiência e lutas de grupos subalternos quanto com a academia formal (ESCOBAR, 2016, p. 13). Além disso, as ES fazem um esforço de tradução que atravessa culturas e buscam paridade entre preocupações e suposições para identificar semelhanças e diferenças e, quando apropriado, desenvolver novas

\footnotetext{
${ }_{18}$ Para Ramos, devemos também desmistificar a crença ocidental (europeia) de que as conquistas comerciais, políticas, filosóficas e científicas são fruto de um esforço único dos europeus: "Como periferia da Ásia, em particular antes da era cristã, a Europa beneficiou-se de inúmeras descobertas do, por ela chamado, Oriente." (RAMOS, 2013, p. 21-22).
} 
formas híbridas de compreensão e comunicação cultural (SANTOS, 2016), bem como Mignolo (2002) observou no caso dos zapatistas. ${ }^{19}$

Santos defende uma compreensão mais ampla do mundo e uma visão de que sua transformação pode estar ocorrendo de maneiras não previstas por muitos dos sistemas de pensamento ocidentais, incluindo o marxismo. Para Santos, o mundo contém uma diversidade infinita, englobando uma multiplicidade de modos de ser; de pensar; de sentir; de conceber o tempo; de relações entre seres humanos e entre humanos e não humanos; como enfrentamos o passado e o futuro coletivamente; e como organizamos a vida, a produção de bens e serviços e o lazer (SANTOS, 2016, p. 20). Este referencial se contrapõe diretamente ao mundo-de-um-único-mundo (One World World), que foi promulgado por meio de práticas epistemológicas e processos históricos relacionados à modernidade, que, por sua vez, facilitaram a visão dominante de uma separação entre humanos e natureza (ESCOBAR, 2016, p. 21).

Além disso, múltiplos sistemas de conhecimento remetem a múltiplos mundos (ESCOBAR, 2016; LING 2014). Escobar (2016) argumenta que esses são "mundos relacionais" nos quais as defesas do território, da vida e dos bens comuns são intrinsecamente a mesma. Nesse sentido, as lutas dos indígenas e de outros povos marginalizados são tidas como lutas ontológicas (ESCOBAR, 2016, p. 13, 20-21). Não se trata apenas de direitos sobre territórios ou direitos de manter suas culturas, crenças, práticas ou capacidades para funcionar (SCHLOSBERG; CARRUTHERS, 2010), mas de resistência a uma ocupação ontológica particular, a do "mundo universal de indivíduos e mercados que tenta transformar todos os outros mundos em um" (ESCOBAR, 2016, p. 21). As lutas das comunidades indígenas, afrodescendentes, camponesas e urbanas pobres são lutas ontológicas em defesa de seus muitos mundos (ESCOBAR, 2016; MIGNOLO, 2002) em um único planeta (INOUE; MOREIRA, 2016).

Mais do que reconhecer esses mundos, poderíamos aprender com eles (SANTOS, 2016, p. 22). Outros sistemas de conhecimento podem oferecer novas possibilidades que o conhecimento científico não consegue prever, especialmente se

\footnotetext{
${ }^{19}$ No caso dos zapatistas, ocorreu um processo de "tradução bidirecional" entre o marxismo e as formas indígenas de saber, no qual o povo maia de Chiapas e o subcomandante Marcos mudaram seus referenciais originais (MIGNOLO, 2002).
} 
considerarmos a real possibilidade de ultrapassarmos os limites planetários (ROCKSTRÖM et al., 2009). Referindo-se à atual crise socioambiental global, Santos (2016, p. 22) afirma: "O conhecimento científico que nos trouxe até aqui não será capaz de nos tirar daqui, precisamos de outros saberes, precisamos de outras concepções de tempo, precisamos de outras concepções de produtividade, precisamos de outras concepções de escala espacial”. De forma análoga, Escobar (2016, p. 21-22) afirma que, com as mudanças climáticas globais, a "ubiquidade da linguagem da crise utilizada para se referir às condições ecológica e social planetárias" e as lutas por montanhas, paisagens, florestas e territórios que remetem às compreensões relacionais e pluri-ontológicas da vida, são evidências do esgotamento do OWW e da necessidade de mudança.

Nesse sentido, há uma necessidade urgente de encontrar outras formas de conceitualizar, pesquisar e praticar a política ambiental/planetária no Antropoceno (WAPNER, 2014). O ambientalismo deve se empenhar em direção a "objetivos transformadores, ecológicos e orientados para a justiça” (DAUVERGNE, 2016, p. 9). Pensar a PAG em termos pluriversais significa ter uma "posição politicamente emancipatória que inclui processos de saber ... e modos de ser no mundo" (QUEREJAZU, 2016, p. 5). Enquanto campo, a PAG deve engajar esses mundos múltiplos para reformular a maneira como estudamos—e, talvez, praticamos—a PAG.

A consideração dos vários sistemas de conhecimento não elimina as iniquidades de poder. É preciso distinguir a integração de conhecimento, as abordagens paralelas de desenvolvimento de sinergias entre sistemas de conhecimento, e a co-produção de conhecimento. Integração remete a processos que tentam incorporar componentes de um sistema de conhecimento a outro por meio de um processo de validação baseado no segundo. A abordagem paralela busca complementaridades, enquanto pressupõe validação entre sistemas de conhecimento, com cada sistema considerado legítimo dentro de seu contexto. Cada um busca o conhecimento em paralelo, enriquecendo o outro. Por fim, a coprodução é um processo mútuo de geração de conhecimento que envolve os atores em todas as etapas, incluindo a validação. Nesse caso, o diálogo epistêmico e ontológico deve ser conduzido em termos iguais e de maneira respeitosa por meio da coprodução de conhecimento e abordagens paralelas (TENGÖ et al., 2014, p. 582). 
Dadas as assimetrias de poder, a coprodução de conhecimento não é simples. Ling e Pinheiro (no prelo) combinam as ES de Santos com a abordagem dos muitos mundos $^{20}$ das relações internacionais para guiar a EFC. A dialógica de muitos mundos tem como premissa três ideias: a relacionalidade, a ressonância e a interexistência (LING, 2014). A primeira identifica assimetrias de poder ao mesmo tempo que reconhece a agência discursiva de, por e para os subalternos e está ligada ao reconhecimento das ES de múltiplas formas de conhecer. A ressonância encoraja a solidariedade política para com vozes silenciadas ou marginalizadas e está associada à justiça epistêmica, identificando semelhanças entre os discursos ou como "um conjunto de articulações em um local vibra com as de outro" (LING, 2014, 21). Finalmente, a interexistência, ou ética com compaixão, orienta a ação de muitos mundos, reconhecendo que "você está em mim e eu em você" (LING, 2014, p. 21), e está relacionada à transformação emancipatória das ES. Esses princípios contribuem para a EFC ou o método "de muitos mundos" de coprodução de conhecimento (LING; PINHEIRO, no prelo).

Relacionalidade, ressonância e interexistência fornecem uma maneira de superar vários impasses que surgem ao tentar se engajar com outras formas de conhecer, como o conhecimento indígena. A partir da marginalização e silenciamento históricos dos povos indígenas, surge a ilusão de que o conhecimento indígena pode ser "transferido" ou "assimilado" pela academia (AGRAWAL, 1995; WILSON, 2004; MARTELLO, 2001). Os "neoindigenistas" acreditam que os estudos sobre o conhecimento indígena podem ser arquivados em centros nacionais ou internacionais enquanto bancos de dados e contam com o mesmo tipo de visão de mundo dicotômica dos teóricos da modernização, criando duas categorias de conhecimento (ocidental e indígena) enraizadas em essencialismos. Neste processo, ignoram a diversidade e heterogeneidade dentro desses sistemas de conhecimento e esquecem que eles não são separados e estáticos ou fixos no tempo e no espaço (AGRAWAL, 1995, p. 420421).

Martello (2001, p. 131) analisa documentos relativos à Convenção sobre Diversidade Biológica, a Convenção para o Combate à Desertificação e um Programa

\footnotetext{
${ }^{20} \mathrm{Na}$ abordagem dos muitos mundos (worldism), os Mundos Múltiplos e o Mundo Vestfaliano se contradizem e se complementam (Ling 2014, p. 15).
} 
do Banco Mundial, em que descobre que a linguagem utilizada ao tratar 0 conhecimento tradicional reflete uma visão que o coloca como um "recurso extraível" a ser padronizado para se tornar compreensível, útil e valioso. Tal visão estabelece uma "dinâmica unilateral" do local para o internacional, com pouco envolvimento das comunidades indígenas e locais (MARTELLO, 2001).

Agência discursiva remonta a todos terem voz em pé de igualdade. As questões indígenas devem ser reformuladas como mudanças nas relações de poder e controle sobre o uso de terras e recursos, incluindo o direito de decidir sobre como resguardar seu conhecimento e quem poderá usá-lo, em vez de colocá-lo em arquivos e centros de conhecimento (AGRAWAL, 1995, p. 431-432) ou tratá-lo como recursos a serem extraídos. As culturas não são fechadas, pois os povos são agentes dinâmicos que mudam com o tempo.

Existe, ainda, o risco de cooptação. Alguns pesquisadores estão mostrando como os princípios indígenas, como o buen vivir, podem ser incorporados às leis e políticas nacionais e, assim, ser usados pelo Estado para manter o controle e o poder (POWESKA, 2017; RANTA, 2017). As ideias de justiça epistêmica e ressonância contribuem para desconstruir dinâmicas unilaterais e a cooptação. O conhecimento emerge de encontros, da co-constituição e da interconexão.

A ética com compaixão e transformação emancipatória pode ajudar a superar os perigos dos discursos "ecoindigenistas" ou "primitivistas" (SISSONS, 2005; CARNEIRO DA CUNHA, 2012, p. 11). O ecoindigenismo coloca o enfoque na proximidade que os povos indígenas mantêm com a natureza, reavaliando "o primitivismo e o tribalismo em relação à racionalidade destrutiva e ao individualismo" (SISSONS 2005, p. 23). Para Sissons, o discurso do ecoindigenismo, ou a ecoetnicidade, enfatiza as relações entre os povos e seus ambientes naturais, mas não considera que a maioria dos indígenas nas sociedades colonizadas agora é urbana. Além disso, existem regimes coloniais e pós-coloniais de autenticidade opressora que distinguem nativos "autênticos e inautênticos", "congelando" os povos indígenas em certas posições e identidades e não reconhecendo o dinamismo das culturas indígenas e a crescente diversidade de identidades indígenas (SISSONS, 2005, p. 28). 
Primitivismo é a ideia de que as sociedades indígenas permaneceram em algum momento do passado, e revelariam como eram as sociedades ocidentais antes da "História" (CARNEIRO DA CUNHA, 2012, p. 11). Essas sociedades têm sua própria (e trágica) história. Por exemplo, sítios arqueológicos evidenciam que a Amazônia foi muito mais povoada antes de 1500, com grandes populações que construíram estradas, assentamentos e artes e ofícios vibrantes (LOPES, 2017; CARNEIRO DA CUNHA, 2012). A transformação emancipatória destaca esse dinamismo e como as pessoas, mesmo as sem voz, lutam para manter seus modos de ser. Por isso, Santos aponta para a possibilidade de aprender com essas lutas.

A EFC requer mudanças nas relações de poder (AGRAWAL, 1995), por meio da desmontagem de binarismos em direção à mutualidade, e uma mudança na relação, não nas posições (Ling e Pinheiro, no prelo), resultando em aprendizagem mútua. A literatura vem discutindo as tentativas de incorporar o conhecimento indígena aos processos de governança global e local foram (KAUFFMAN; MARTIN, 2014; SUISEEYA, 2014; BERRY et al., 2018). Embora esses trabalhos destacam a importância dos conhecimentos indígenas, o foco não está na agência discursiva e na paridade entre os sistemas de conhecimento.

Ling e Pinheiro (no prelo) sugerem que (re)nomear pode ser uma forma criativa de transformar relacionamentos, liberando o que obstrui o fluxo da comunicação. Por exemplo, muitos povos indígenas têm reservas sobre conceitos como "recursos naturais" e "serviços ecossistêmicos" porque eles conflitam com suas visões de mundo (KAUFFMAN; MARTIN, 2014; ATHAYDE, 2015). A propriedade é outro conceito problemático para alguns povos indígenas, que "têm uma relação 'horizontal' com os seres, ao invés de possuir propriedade ou controle sobre eles" (ATHAYDE, 2015, p. 51). Para que "aconteça uma escuta verdadeira, todos os elementos de uma troca precisam ser reorganizados, dando-Ihe uma nova forma ou significado", ${ }^{21}$ o que inclui nossas noções relacionadas a meio ambiente e natureza.

Um terceiro espaço ou um "oásis global" pode ser imaginado, ou pode ser um lugar real para explorações criativas ${ }^{22}$ (LING; PINHEIRO, no prelo). Procuro aqui criar

\footnotetext{
${ }^{21}$ Carolina Pinheiro, entrevista por e-mail com a autora, 5 de fevereiro de 2018.

22 Lily Ling criou um projeto em que discute RI enquanto explora receitas de pratos tradicionais de diferentes regiões. O pressuposto é que os alimentos podem comunicar mais sobre mundos
} 
um terceiro espaço para ouvir Davi Kopenawa, um xamã yanomami. Considero o livro A queda do céu um exercício de EFC (embora não seja nomeado como tal) entre ele e Bruce Albert, um antropólogo, que traduziu as palavras de Kopenawa (agência discursiva) e explicou como elas ressoam com o conhecimento acadêmico. O livro revela a mutualidade e uma nova relação entre esses sistemas de conhecimento.

\section{Ouvindo o Mundo-Floresta: Formas Indígenas de Conhecer, a "Queda do Céu" e o Antropomorfismo}

Relacionalidade: formas indígenas de conhecer

As formas de conhecer dos povos indígenas são baseadas em fontes diferentes e expressas de maneiras diferentes. Relacionalidade, ou agência discursiva, implica paridade entre as formas de conhecer e ressalta a importância de ouvir uma miríade de vozes. Algumas pessoas fazem uso de histórias, poemas, mitos, sonhos, textos escritos e canções. Assim como no romance de Le Guin, que nos conta como os athsheanos aprendiam sobre o mundo por meio dos sonhos, os sonhos também são muito importantes para os Yanomami e outros povos indígenas da Amazônia. Os sonhos informam a maneira em que dão sentido aos princípios invisíveis do mundo (DANOWSKI; VIVEIROS DE CASTRO, 2017, p. 103). As epistemologias ocidentais, em contraste, não valorizam os sonhos. Além disso, os sonhos nas epistemologias ocidentais ocorrem a partir da perspectiva da primeira pessoa, que Danowski e Viveiros de Castro (2017, p. 104) consideram um indício de nosso narcisismo e a incapacidade de estar aberto a uma infinidade de agências no cosmos. Kopenawa ecoa esse sentimento quando afirma,

Os brancos não sonham tão longe quanto nós. Dormem muito, mas só sonham com eles mesmos. Seu pensamento permanece obstruído e eles dormem como antas ou jabutis. Por isso não conseguem entender nossas palavras. (KOPENAWA; ALBERT, 2013, p. 313) ${ }^{23}$

diferentes do que os conceitos convencionais de RI (Carolina Pinheiro, entrevista por email com a autora, 16 de junho de 2018).

${ }^{23}$ N. T. Na edição brasileira, p. 390.

Monções: Revista de Relações Internacionais da UFGD, Dourados, v.9, n.18, jul./dez. 
Além disso, o conhecimento dos Yanomami não é "desenhado" (escrito), pois eles acreditam que sua "memória é longa e forte". Seu conhecimento é baseado em "palavras pronunciadas pela boca", a partir daquilo que vêem quando tomam o pó de yãkoana ${ }^{24}$, e no que os espíritos Ihes dizem durante o sonho (KOPENAWA; ALBERT, 2013 , p. 24). Kopenawa afirma que não teve que ler para aprender sobre a floresta e que "[viu]-as de verdade, bebendo o sopro de vida de [seus] antigos com o pó de yākoana"25. Para ele, isso também proporciona o "sopro dos espíritos", multiplicando suas palavras e ampliando seus pensamentos (KOPENAWA; ALBERT, 2013, p. 24).

Interessante notar que Ailton Krenak, outro líder indígena, tem uma perspectiva diferente. Para ele e seu povo, ler e escrever podem ser uma forma de aprendizagem, mas eles consideram a alfabetização uma técnica como dirigir ou operar uma máquina. Para eles, tudo tem um valor certo e a alfabetização é apenas uma entre muitas habilidades (KRENAK, 2015, p. 85).

Cesarino et al. (2013) organizam e traduzem poemas dos Marubo, que habitam o estado do Amazonas no Brasil. Em seus poemas, os Marubo expressam sua sabedoria. Kana Voã é a "cabeça dos espíritos" para eles. Sua noção de divindade não é a de um pai hierárquico criador do mundo com um monólogo imperativo; ao contrário, a criação deriva de uma decisão dialógica: um diálogo entre entidades que são pares, ou irmãs, e que discorrem entre si sobre uma terra para futuros habitantes. Da mesma forma, os Desana do Alto Rio Negro falam sobre o criacionismo em termos de uma conversa entre dois demiurgos, Baaribo e Burupu (CESARINO et al., 2013, p. 44-45).

Como mencionado acima, os estudiosos argumentam que os mitos e as histórias indígenas não devem ser tratados como se fossem fantasia, imaginação ou ficção, como algo em oposição às afirmações científicas ou históricas objetivas da verdade; tampouco devem ser elevados ao patamar de uma solução mística ou romântica para nossa crise (CESARINO et al., 2013, p. 19-20; WILSON 2004). Ao contrário, devem ser julgados em seus respectivos contextos, em prol de uma atitude comprometida em garantir a autodeterminação ontológica dos outros (CESARINO et

${ }^{24}$ Yākoana hi ou yākoana a: Virola elongata, ucuuba-vermelha; árvore de cuja resina é fabricado o pó alucinógeno yākoana a, cujo principal princípio ativo é a dimetiltriptamina (Glossário Etnobiológico, em KOPENAWA e ALBERT, 2013, p. 584). N. T. Na edição brasileira, p. 597.

${ }^{25}$ N. T. Na edição brasileira, p. 76. 
al., 2013, p. 20, referindo-se a Eduardo Viveiros de Castro). Esta é uma condição para que a EFC aconteça, o que abre a possibilidade de aprendizagem mútua. A profecia da "queda do céu" dos Yanomami pode, por exemplo, nos ensinar algo sobre a possibilidade de um colapso ecológico a partir da destruição da floresta amazônica.

Ressonância: Salvar a Amazônia, impedir que o céu caia?

Os Yanomami são atacados por defenderem suas terras na floresta, Urihi a. No Brasil, os povos indígenas continuam a ser submetidos à violência brutal, a marginalização, a invasões de terras e a exploração. O garimpo de ouro, a expansão da infraestrutura, da agricultura e da pecuária, e a exploração de madeira e outros recursos colocaram uma pressão crescente sobre suas terras florestais e impulsionaram grande parte dessa violência. Por exemplo, entre 2009 e 2017, 891 indígenas foram assassinados em todo o território brasileiro, ${ }^{26}$ sendo que os povos indígenas representam aproximadamente $38 \%$ de todos os assassinados nas áreas rurais do país. Entre eles, os Yanomami sofreram algumas das maiores taxas de mortes e violência física (CONSELHO INDIGENISTA MISSIONÁRIO, 2016). Além dessa ameaça existencial ao seu território, para Kopenawa, a ameaça a este mundofloresta é, de fato, uma ameaça para o mundo inteiro.

Kopenawa afirma que os "brancos" não entendem porque seu povo quer manter sua floresta. Ele ouviu palavras de advertência de grandes xamãs e que os "brancos" deveriam sonhar mais e prestar atenção às vozes do espírito da floresta: "[Sua] forma de pensar é outra. Eles não sabem realmente as coisas da floresta" (KOPENAWA; ALBERT, 2013, p. 22, 410).

Conca e Dabelko (2015, p. 2) enfatizam que existem diferentes visões sobre a floresta e que a PAG evolui em torno de tentativas de conciliar essas visões, de encontrar um equilíbrio entre elas, ou de lutar para tornar uma proeminente. No entanto, nos últimos anos, uma visão dominante da floresta parece estar emergindo, uma que a valoriza na medida em que apresenta uma função instrumental, de

\footnotetext{
${ }^{26}$ Veja http://especiais.correiobraziliense.com.br/517anosderesistencia, acessado pela última vez em 18 de janeiro de 2018.
}

Monções: Revista de Relações Internacionais da UFGD, Dourados, v.9, n.18, jul./dez. 
armazenamento carbono ou proteção à biodiversidade. ${ }^{27}$ Embora salvar a Amazônia seja fundamental para alcançar a redução das emissões de carbono advindas do desmatamento, além de conservar a biodiversidade e os ciclos hidrológicos e climáticos, para povos como os Yanomami, há muito mais envolvido na luta pela manutenção da floresta. A floresta é o seu mundo.

Argumentar que a floresta é o seu mundo não é reduzir sua luta a uma história de ficção como a do romance de Le Guin. Estudos arqueológicos, etnobotânicos e etno-históricos demonstram que a Amazônia é habitada há milhares de anos. Nunca foi uma floresta imaculada e intocada. Em alguns lugares, foi mais densamente povoado antes de 1500 do que é hoje; ali, mostrou sinais de manejo indígena, de esgotamento de recursos e até de crise ecológica (SCHWARTZMAN et al., 2000; LOPES, 2017; CARNEIRO DA CUNHA, 2012). A Amazônia é, de fato, o resultado de interações dinâmicas entre seus habitantes.

Hoje, os povos indígenas e as comunidades tradicionais que vivem na floresta amazônica são os principais responsáveis por sua proteção. Terras/territórios indígenas atuam como obstáculos ao avanço do desmatamento e às associadas emissões de carbono. Estudos demonstram que as terras indígenas estão entre as mais preservadas em termos de cobertura florestal e biodiversidade. Além disso, essas terras contribuem, ainda, para deter o desmatamento fora de seus limites, cobrindo distâncias de até dez quilômetros (RICKETTS et al., 2010). Os Yanomami consideram a proteção de suas terras florestais de fundamental importância não só para garantir os recursos necessários à sua sobrevivência, mas também para o equilíbrio do mundo inteiro e para manter intactas as forças de sua ordem cosmológica: as trovoadas, os ventos, as tempestades, o dia e a noite, a caça e a fertilidade (KOPENAWA; ALBERT, 2013). Os xamãs protegem os habitantes da floresta e todos os demais. As invasões de suas terras poderiam resultar na morte de todos os xamãs, que, por sua vez, não poderiam mais evitar que a floresta se transformasse em um caos. O Maxitari, o ser da terra, e Titiri, o ser da noite, ficarão

\footnotetext{
${ }^{27}$ Uma contagem de frequência de palavras do NVivo evidencia a proeminência de temas relacionados ao clima. Em 427 artigos (2001-2016), a primeira palavra mais frequente é clima. Política, mudança, governança e países vêm logo depois. Carbono é a vigésima quinta palavra mais frequente; a floresta vem depois na vigésima nona posição. Biodiversidade, povos indígenas, justiça e sustento não figuram entre as cem palavras mais frequentes.
} 
enfurecidos, e os xamãs não estarão lá para deter Titiri (KOPENAWA; ALBERT, 2013, p. 405):

A floresta ficará escura e fria e assim permanecerá para sempre. Não terá mais amizade para nós .... Então as águas cobrirão, gradualmente, toda a terra e os humanos se tornarão outros, assim como aconteceu no início dos tempos .... O céu, que estão tão nauseados da fumaça dos brancos como nós, começará a gemer e a se despedaçar ... Então, não haverá um único xamã para segurá-lo. (KOPENAWA; ALBERT, 2013, p. 405-406)

Para os Yanomami, se a floresta morrer, os xamãs morrerão e não poderão invocar os espíritos xapiri, necessários para impedir que o céu caia (DANOWSKI; VIVEIROS DE CASTRO, 2017, p. 104; KOPENAWA; ALBERT, 2013). Salvar a Amazônia significa salvar o seu assim como o nosso mundo. Para entender por que a floresta transmite tanto poder, é importante tentar vê-la como eles o fazem. A ressonância fomenta a solidariedade política para com vozes silenciadas ou marginalizadas. Assim, a tentativa de compreender o mundo-floresta pode contribuir para o alcance da justiça epistêmica e a compreensão de que a afirmação dos Yanomami sobre o destino da floresta amazônica não está muito longe do que a ciência vem demonstrando.

Interexistência: a palavra para mundo é floresta - antropomorfismo e a floresta como sociedade de sociedades

A floresta para os Yanomami e outros povos indígenas da Amazônia é uma entidade viva onde humanos, animais, espíritos e outros seres coexistem e interagem. Como mencionado acima, urihi a é sua terra florestal e urihinari é o espírito da floresta que dá vida aos seres da floresta. Essa compreensão é semelhante à visão de outros povos indígenas. Por exemplo, para os Tukano, que vivem na Amazônia brasileira e colombiana, a natureza, os animais e os seres humanos foram criados juntos e dependem uns dos outros. Inicialmente, os seres humanos podiam se casar com os animais, porque os humanos foram criados por meio de uma mistura de floresta e animais. Consequentemente, havia árvores e animais na floresta com o mesmo sangue de seres humanos (CABALZAR, 2010, p. 21-37). Na Amazônia Central, os 
Xerente $^{28}$ acreditam que tudo, desde rios e florestas a animais, possui uma alma independente e é controlado e cuidado pelos espíritos sobrenaturais correspondentes. Esses espíritos interferem diretamente em suas atividades diárias, como na pesca, na caça, no plantio e na colheita. Suas histórias ensinam que deve haver respeito entre esses elementos e que o aprendizado pode ocorrer por meio dessas interações (MELO, 2000). Os Manxineru da Amazônia Ocidental (no Acre) também acreditam que os animais e os rios têm espíritos e que as pessoas recebem seus nomes dos animais (MACHINERI, 2013).

Para os Yanomami e muitas cosmovisões amazônicas (Ashaninka / Campa, Yawanawa, Aikewara), os humanos são empiricamente anteriores ao mundo. O antropomorfismo significa que tudo é humano: "Humanos-queixada viraram queixadas; humanos-veado viraram veados" (KOPENAWA; ALBERT, 2013, 60-61). Uma espécie de humanidade primordial (às vezes criada por um demiurgo) existia como o único substrato ou matéria a partir da qual o mundo foi formado (DANOWSKI; VIVEIROS DE CASTRO, 2017, p. 91). Os animais surgiram desses humanos anteriores. Porções desta humanidade se transformaram em animais, plantas, outros seres vivos, fenômenos meteorológicos e partes do cosmos (estrelas, a lua, etc.) espontaneamente ou pela ação de um demiurgo. Essas porções que não se transformaram em outra coisa constituem a humanidade histórica ou presente (p. 9192). Danowski e Viveiros de Castro contrastam o antropomorfismo ontológico dos ameríndios com o antropocentrismo ocidental. Em sua opinião, o primeiro é o inverso do último: "Dizer que tudo é humano é o mesmo que dizer que os humanos não são uma espécie especial" (p. 99, 100-101). Normalmente, o ataque ao antropocentrismo é baseado em afirmações de que os humanos são animais, seres vivos ou sistemas materiais. O antropomorfismo, ao contrário, afirma que os animais e outras entidades são "humanos como nós" (p. 101-102). Essa inversão do argumento está muito em sintonia com a noção do Antropoceno; ao remover a "natureza" como um "outro",

\footnotetext{
${ }^{28}$ Os Xerente contam atualmente com aproximadamente três mil habitantes, que vivem no centro do estado do Tocantins em dois territórios legalmente demarcados. Apesar das inúmeras ameaças ao seu território devido à introdução de barragens hidrelétricas, estradas pavimentadas, hidrovias e agricultura intensiva, o sustento, cultura e tradições dos Xerente ainda estão intensamente relacionados à natureza.
} 
podemos mudar a maneira como nos relacionamos com o mundo mais do que humano, eliminando as dicotomias e distinções hierárquicas.

Assim, para vários povos indígenas da Amazônia, a dicotomia sociedadenatureza não faz sentido. O "mundo natural", ou o mundo inteiro, é uma "multiplicidade de multiplicidade" intrinsecamente conectada. Animais e outras espécies são considerados outros tipos de "gente" e "gente" e, como entidades políticas, vivem em suas sociedades (DANOWSKI; VIVEIROS DE CASTRO, 2017, p. 97-98). A floresta (ou natureza) é um conjunto de sociedades como uma "arena internacional", constituída por ex-humanos, ${ }^{29}$ que, segundo alguns povos indígenas, retinha um lado humano latente ou secreto. ${ }^{30}$ Tudo é literalmente político, pois não há diferença absoluta de status entre a sociedade e o meio ambiente (p. 98). Assim, não há natureza senão uma "sociedade de sociedades", onde tudo tem vida própria e uma imagem / espírito. A floresta e até mesmo a água estão vivas (KOPENAWA; ALBERT, 2013, p. 382). Por isso, faz sentido falar do mundo-floresta, e a "ética com compaixão" pode nos orientar a falar com os povos da floresta e a respeitar todos os seres da "sociedade das sociedades".

\section{Conclusões: PAG como um terceiro espaço para a EFC em relação ao mundo-floresta?}

Abordar a PAG pelos múltiplos mundos significa questionar e refletir sobre as formas como produzimos e validamos o conhecimento e como o conhecimento constitui nossos mundos, bem como reconhecer que múltiplas formas de conhecer remetem a múltiplos mundos, também tido como o pluriverso. Não é o suficiente reconhecer a existência de muitos mundos ou muitos reais e muitas formas de conhecer. É importante aprender com os mesmos (SANTOS, 2016; ESCOBAR, 2016).

As lutas dos povos indígenas para manter a posse de terras, florestas, água, montanhas, conhecimentos e modos de ser também são lutas para manter os

\footnotetext{
${ }^{29}$ Não humanos são vistos como ex-humanos.

${ }^{30}$ Esta condição oculta não pode ser vista por humanos em condições normais, mas os xamãs podem vê-la em seu transe.
} 
mundos. Enquanto estudiosos, podemos aprender com esses mundos. Este artigo tentou criar um "terceiro espaço" para a EFC. Este é apenas o primeiro passo; um mais ambicioso seria reunir-nos em conferências e outros espaços onde poderíamos desenvolver a mutualidade e co-produzir conhecimento. A despeito das assimetrias de poder e de diversos tipos de violência, os povos indígenas são agentes e conhecedores que desenvolvem seus próprios conceitos a partir dos quais podemos encontrar ressonância.

Para ouvir os povos da floresta, é necessário reconhecer sua agência discursiva. Além disso, a paridade epistêmica e ontológica é uma forma de transformar relacionamentos em mutualidade e não simplesmente em uma inversão de polos. Procurei, por meio da aplicação dos princípios de relacionalidade, ressonância e interexistência, ouvir as vozes indígenas na Amazônia, especialmente as dos Yanomami, que têm lutado para manter seu mundo-floresta. Suas formas de conhecer envolvem sonhos, profecias, histórias, mitos e ainda textos escritos. Engajar-se com essas formas de conhecer é importante para entender o mundo da floresta como uma entidade viva habitada por humanos e ex-humanos, que se transformaram em animais e outros seres. Para os Yanomami e demais povos indígenas, o ser humano não é uma ser excepcional, nem é o único que possui inteligência e espiritualidade; por isso não deve ser tratado como se pertencesse ao topo da cadeia evolutiva. Os animais e a "natureza" também são o futuro da humanidade, e não apenas seu passado (DANOWSKI; VIVEIROS DE CASTRO, p. 93-95).

Essa noção é pertinente para reconceber a política ambiental e as relações com o mundo mais do que humano no Antropoceno (WAPNER, 2014). O mundofloresta é uma sociedade de sociedades (DANOWSKI; VIVEIROS DE CASTRO, 2017) cujo equilíbrio é delicado porque tudo se relaciona entre si. Além disso, ao trazer o lema "salve a Amazônia" em diálogo com a profecia da "queda do céu" dos xamãs yanomami, podemos adquirir novos significados sobre a floresta. Para os Yanomami, manter o mundo-floresta garante que o "céu não caia" ou a coexistência de muitos mundos. Há ressonância para os estudiosos da PAG, pois poderíamos melhor reconhecer e valorizar outras formas de ser e conhecer e ainda aprender com os mesmos. Talvez, se ajudarmos a manter o mundo-floresta, o céu não cairá.

455 
Eu gostaria de homenagear a memória de Lily Ling, que faleceu em outubro de 2018. Lily sempre me incentivou e me inspirou a abraçar a diversidade e os muitos mundos.

Cristina Yumie Aoki Inoue é Professora-Associada do Instituto de Relações Internacionais da Universidade de Brasília. Foi Visiting Fellow (2016-2017) da School of Global Environmental Sustainability, da Colorado State University, onde começou a trabalhar em seu projeto da abordagem dos muitos mundos na PAG. Atualmente é uma das principais coordenadoras da Iniciativa de Novas Direções do Projeto de Governança do Sistema Terra. Suas áreas de pesquisa e atuação são socioambientalismo na Amazônia brasileira, governança do clima e da biodiversidade, Objetivos de Desenvolvimento Sustentável, redes transnacionais e cooperação SulSul.

\section{Referências}

ACHARYA, Amitav; BUZAN, Barry. Why is there no non-Western international theory? an introduction. In: ACHARYA, Amitav; BUZAN, Barry (ed.). Non-Western international relations theory: perspectives on and beyond Asia. Londres: Routledge, 2010. p. 125.

AGRAWAL, Arun. Dismantling the divide between Indigenous and scientific knowledge. Development and Change, v. 26, n. 3, p. 413-439, 1995.

ATHAYDE, Simone. Indigenous knowledge systems and social-environmental management of pollination and pollinators in the Xingu Indigenous Park, Brazilian Amazon. In: LYVER, P. (ed.). Indigenous and local knowledge about pollination and pollinators associated with food production outcomes from the Global Dialogue Workshop. Paris: UNESCO, 2015. p. 46-54.

BERRY, K. A; JACKSON, Sue; SAITO, Laurel; FORLINE, Louis. Reconceptualising water quality governance to incorporate knowledge and values: case studies from Australian and Brazilian Indigenous communities. Water Alternatives, v. 11, n. 1, p. 40-60, 2018.

CABALZAR,, A. Dahsea Hausirõ Porã uk ushe Wiophesase merã bueri turi. In: Mitologia Sagrada dos Tukano Hausirõ. São Gabriel da Cachoeira, Amazonas, 2010.

CARNEIRO DA CUNHA, Manuela. Índios no Brasil. História, direitos e cidadania. São Paulo: Claro Enigma, 2012. 
CESARINO, Pedro de Niemeyer; MARUBO, Armando Mariano; MARUBO, Antonio Brasil; MARUBO, Paulo Joaquim; MARUBO, Lauro Brasil; MARUBO, Robson Dionísio Doles. Quando a Terra deixou de falar. Cantos da mitologia Marubo. São Paulo: Editora 34, 2013.

CHASEK, Pamela; DOWNIE, David L.; BROWN, Janet Welsh. Global Environmental Politics. 7th ed. Boulder, CO: Westview Press, 2017.

CONCA, Ken; DABELKO, Geoffrey D. Introduction: from Stockholm to sustainability? In: CONCA, Ken; DABELKO, Geoffrey (ed.). Green planet blues: critical perspectives on Global Environmental Politics. 5th ed. Boulder, CO: Westview Press, 2015.

CONSELHO INDIGENISTA MISSIONÁRIO. Relatório Violência contra os Povos Indígenas no Brasil-Dados de 2016. 2016. Disponível em: https://tinyurl.com/y7ksx9bw. Acessado em: 12 fev. 2018.

DANOWSKI, Déborah; VIVEIROS DE CASTRO, Eduardo. Há mundo por vir? Ensaios sobre os medos e os fins. 2. ed. Série: Cultura e Bárbarie, Instituto Socioambiental, Desterro, 2017.

DAUVERGNE, Peter. Research in Global Environmental Politics: history and trends. In: DAUVERGNE, Peter (ed.). Handbook of Global Environmental Politics. Nova York: Edward Elgar, 2005.

DAUVERGNE, Peter. Environmentalism of the rich. Cambridge, MA: MIT Press, 2016.

ESCOBAR, Arturo. Thinking-feeling with the Earth: territorial struggles and the ontological dimension of the epistemologies of the South. Revista de Antropología Iberoamericana, v. 11, n. 1, p. 11-32, 2016.

INOUE, Cristina Yumie Aoki; MOREIRA, Paula Franco. Many worlds, many nature(s), one planet: Indigenous knowledge in the Anthropocene. Revista Brasileira de Política Internacional, v. 59, n. 2, p. e009, 2016. Disponível em: https://doi.org/10.1590/00347329201600209.

INOUE, Cristina; TICKNER, Arlene B. Many worlds, many theories? Revista Brasileira de Política Internacional, v. 59, n. 2, p. e009, 2016. Disponível em: https://doi.org/10.1590/0034- 7329201600209.

KAUFFMAN, Craig M.; MARTIN, Pamela L. Scaling up buen vivir: globalizing local environmental governance from Ecuador. Global Environmental Politics, v. 14, n. 1, p. 40-58, 2014.

KOPENAWA, Davi; ALBERT, Bruce. The falling sky: words of a Yanomami shaman. Cambridge, MA: The Belknap Press of Harvard University Press, 2013.

KRENAK, Ailton. Encontros. Rio de Janeiro: Azougue, 2015. 
LE GUIN, Ursula K. The word for world is forest. San Francisco, CA: Masterworks, 1976.

LEIS, Héctor Ricardo. A modernidade insustentável. As críticas do ambientalismo à sociedade contemporânea. Petrópolis: Editora Vozes, 1999.

LING, Lily H. M. The Dao of world politics: towards a post-westphalian worldist International Relations. Londres: Routledge, 2014.

LING, Lily H. M.; PINHEIRO Carolina M. South-South talk: worldism and epistemologies of the South. In: TICKNER, Arlene B.; SMITH, Karen. Theorizing international politics from the global South: worlds of difference. New York: Routledge, No Prelo.

LOPES, Reinaldo José. 1499: A pré-história do Brasil. Rio de Janeiro: HarperCollins, 2017.

MACHINERI, Lucas Artur Brasil. A língua manxineru e as relações de parentesco junto aos Animas da floresta amazônica. Manuscrito não publicado, Universidade Federal do Acre, Cruzeiro do Sul, Brasil, 2013.

MARTELLO, Marybeth Long. A paradox of virtue? "Other" knowledges and environment-development politics. Global Environmental Politics, v. 1, n. 3, p. 114$141,2001$.

MARTINEZ-ALIER, Joan. The environmentalism of the poor: a study of ecological conflicts and valuation. Cheltenham, UK: Edward Elgar, 2002.

MELO, Valéria Moreira Coelho de. Diversidade, meio ambiente e educação: uma reflexão a partir da sociedade Xerente. 2000. Dissertação de mestrado, CIAMB/UFT, 2000.

MIGNOLO, Walter D. The Zapatista's theoretical revolution: its historical, ethical, and political consequences. Utopian Thinking, v. 25, n. 3, p. 245-275, 2002.

NICHOLSON, Simon; JINNAH, Sikina. Living on a New Earth. In: NICHOLSON, Simon; JINNAH, Sikina. New Earth politics: essays from the Anthropocene. Cambridge, MA: MIT Press, 2016. p. 1-19.

POWESKA, Radoslaw. State-led extractivism and the frustration of Indigenous selfdetermined development: lessons from Bolivia. International Journal of Human Rights, v. 21, n. 4 , p. $442-463,2017$.

QUEREJAZU, Amaya. Encountering the pluriverse: looking for alternatives in other worlds. Revista Brasileira de Política Internacional, v. 59, n. 2, p. e007, 2016. Disponível em: https://doi.org/10.1590/0034-7329201600207. 
RAMOS, Alcida. Mentes indígenas e ecúmeno antropológico. Série Antropologia 439. Departamento de Antropologia, Universidade de Brasília, 2013.

RANTA, Eija Maria. Vivir bien governance in Bolivia: chimera or attainable utopia? Third World Quarterly, v. 38, n. 7, p. 1603-1618, 2017. Disponível em: https://doi.org/10.1080/01436597.2016.1224551.

RICKETTS, Taylor H.; SOARES-FILHO, Britaldo; FONSECA, Gustavo A. B. da et al. Indigenous lands, protected areas, and slowing climate change. PLoS Biology, v. 8, n. 3, p. 6-9, 2010.

ROCKSTRÖM, J.; STEFFEN, W.; NOONE, K.; PERSSON, Å.; CHAPIN III, F. S.; LAMBIN, E.; LENTON, T. M. et al. Planetary boundaries: exploring the safe operating space for humanity. Ecology and Society, v. 14, n. 2, p. 32 Disponível em: www.ecologyandsociety.org/ vol14/iss2/art32/.

RUDY, Alan P.; WHITE, Damian. Hybridity. In: DEATH, Carl. Critical Environmental Politics: Interventions. Londres: Routledge, 2014.

SANTOS, Boaventura de Sousa. Epistemologies of the South and the future. From the European South, v. 1, p. 17-29, 2016.

SCHLOSBERG, David; CARRUTHERS, David. Indigenous struggles, environmental justice, and community capabilities. Global Environmental Politics, v. 10, n. 4, p. 12$35,2010$.

SCHWARTZMAN, Stephan; NEPSTAD, Daniel Curtis; MOREIRA, Adriana G. Arguing tropical forest conservation: people versus parks. Conservation Biology, v, 14, n. 5, p. 1370-1374, 2000.

SISSONS, Jeffrey. First peoples: Indigenous cultures and their futures. Londres: Reaktion Books, 2005.

SUISEEYA, Kimberly R. Marion. Negotiating the Nagoya Protocol: Indigenous demands for justice. Global Environmental Politics, v. 14, n. 3, p. 102-124, 2014. Disponível em: https://doi.org/ 10.1162/GLEP_a_00241.

TENGÖ, Maria; BRONDIZIO, Eduardo S.; ELMQVIST, Thomas; MALMER, Pernilla; SPIERENBURG Marja. Connecting diverse knowledge systems for enhanced ecosystem governance: the multiple evidence base approach. AMBIO, v. 43, n. 5, p. 579591, 2014. Disponível em: https://tinyurl.com/y83eeypa. Acessado em: 29 nov. 2016.

TICKNER, Arlene B.; BLANEY, David L. Introduction: thinking difference. In: TICKNER, Arlene; BLANEY, David (ed.). Thinking international relations differently. Londres: Routledge, 2012.

WAPNER, Paul. Living Through the end of nature: the future of American environmentalism. Cambridge, MA: MIT Press, 2010. 
WAPNEr, Paul. The changing nature of nature: environmental politics in the Anthropocene. Global Environmental Politics, v. 14, n. 4, p. 36-54, 2014.

WILSON, Angela Cavender. Reclaiming our humanity: decolonization and the recovery of Indigenous knowledge. In: MIHESUAH, Devon Abott; WILSON, Angela Cavender (org.). Indigenizing the academy: transforming scholarship and empowering communities. Lincoln, NE: University of Nebraska Press, 2004. 